\title{
O homem que calculava, de Malba Tahan: uma pseudotradução do árabe com direito a autor e tradutor fictícios
}

Amarílis Lage de Macedo*

\section{Introdução}

O romance $O$ homem que calculava marcou a infância de muitas gerações de brasileiros. Ambientado em Bagdá e centrado nas aventuras de Beremiz, jovem prodígio da matemática, o livro foi lançado em 1937 e se tornou um verdadeiro fenômeno editorial - está em sua 95a edição no Brasil e já foi traduzido para vários idiomas, incluindo espanhol, inglês, francês e alemão. A obra também despertou o interesse de diversos pesquisadores, que investigaram, por exemplo, seu impacto no ensino da matemática e aspectos relacionados a sua autoria: atribuído a um escritor árabe, chamado Malba Tahan, o livro foi na verdade escrito por um professor de matemática brasileiro, chamado Júlio César de Mello e Souza (1895-1974).

Contudo, um aspecto que parece não ter recebido ainda a devida atenção é que este romance, assim como outros livros assinados por Malba Tahan, são pseudotraduções. Mello e Souza criou até um tradutor fictício para alguns de seus livros, incluindo O homem que calculava: trata-se de Breno Alencar Bianco, que tem uma presença bem forte na obra, assinando quase 200 notas de tradução e um apêndice de aproximadamente 60 páginas.

Este artigo visa propor uma análise inicial de $O$ homem que calculava sob a perspectiva dos Estudos da Tradução. A expectativa é que essa abordagem ajude a iluminar elementos formais e semânticos da obra, assim como o contexto em que ela foi produzida. Além disso, traz para a

\footnotetext{
* Programa de Pós-Graduação em Estudos da Linguagem, Pontifícia Universidade Católica do Rio de Janeiro (PUC-Rio)
} 
historiografia da tradução no Brasil um caso intrigante, que expõe quão complexo é o tema das pseudotraduções.

\section{Método de pesquisa}

As reflexões do teórico israelense Gideon Toury (1942-2016) servem de ponto de partida para a metodologia adotada neste trabalho. Afinal, é ele o maior defensor das pseudotraduções como objeto legítimo no campo dos Estudos da Tradução. Para Toury, quando abrimos mão da noção idealizada do que "deve ser uma tradução" para observar o que efetivamente circula como tal numa cultura, nos deparamos com diversos tipos de texto. Alguns são como colchas de retalhos, produzidos a partir de vários textos fonte. Outros remetem a um texto fonte que já se perdeu. Podemos encontrar traduções diretas e indiretas; traduções em que o componente formal do texto fonte foi reproduzido ou não. E também textos escritos no idioma local que foram, por algum motivo, apresentados (e recebidos) como se fossem traduções.

Diante dessa diversidade, Toury propõe, para a estruturação metodológica dos estudos descritivos em tradução, que os textos selecionados atendam a três postulados: (i) o do texto fonte, (ii) o da transferência e (iii) o da relação. Com base nessa proposta, é possível dizer que um texto ocupa o posto de tradução em determinada cultura quando aquela comunidade (i) presume a existência de um texto fonte, que teria prioridade temporal em relação ao traduzido; (ii) pressupõe que houve a transferência de alguns aspectos do texto fonte para o texto traduzido e, por fim, (iii) acredita que há uma relação significativa entre os dois textos, o que faz com que a tradução exerça na cultura meta uma função semelhante à exercida pelo texto fonte na cultura fonte.

Ora, pseudotraduções podem atender esses postulados tanto quanto qualquer texto efetivamente traduzido. É preciso destacar, porém, que isso não significa que elas levantem o mesmo tipo de questão e conduzam ao mesmo tipo de resposta.

Segundo Toury, as pseudotraduções constituem uma boa fonte de dados, por exemplo, para a identificação dos parâmetros que norteiam a atividade tradutória em dada cultura. Isso porque, quando o autor tenta conferir a seu texto a a parência de uma tradução, ele acaba por inserir marcas textuais que corroborem esse "disfarce". "Ao realçar a semelhança de seus textos com traduções genuínas, eles facilitam que o texto seja considerado 
como tal1"2, escreve Toury, em "Pseudotranslations and their Significance" (2012, p. 53). Assim, as marcas textuais das pseudotraduções oferecem, assim como pronunciamentos normativos (prefácios, resenhas, entrevistas etc.), um testemunho acerca das características que aquela sociedade espera encontrar quando lê uma tradução.

Além disso, Toury elenca uma série de discussões específicas que esse tipo de texto suscita. Entre elas, estão: por que o autor optou por recorrer a esse disfarce? Que fatores fizeram com que essa língua fosse escolhida como fonte, em vez de outra? Que dispositivos levaram o público a acreditar nesse disfarce - e por quanto tempo? (TOURY, 2012, p. 47).

\begin{abstract}
De um ponto de vista evolutivo, o aspecto mais significativo da produção e distribuição de textos escritos na língua alvo como se fossem traduções para a língua alvo é o fato de que essa estratégia oferece uma forma conveniente e relativamente segura de romper com padrões estabelecidos e introduzir novidades numa cultura, e não apenas no campo da literatura (TOURY, 2012, p. 48)
\end{abstract}

Por trás dessa estratégia está a percepção de que, como as traduções costumam ocupar posições secundárias no polissistema literário, é de se esperar que o público seja mais tolerante quando desvios ou novidades aparecem nesse tipo de texto.

A produção de pseudotraduções também pode ser motivada, diz Toury, pelo desejo de driblar a censura em regimes autoritários - muito embora existam exemplos de pseudotraduções que foram encomendadas justamente por governos autoritários, como forma de propagar suas ideias junto à população.

Para ele, é ingênuo supor que uma pseudotradução seja produzida visando apenas sucesso comercial - mesmo quando este é o caso, diz Toury, a situação aponta para questões mais amplas. Uma delas: por que existe a

\footnotetext{
${ }^{1}$ Esta e as demais traduções de citações extraídas de obras em língua inglesa são de minha autoria.

${ }^{2}$ No original: "By enhancing the resemblance of their texts to genuine translations they would be making it easier for their texts to pass as such".

${ }^{3}$ No original: "From the evolutionary point of view, the most significant aspect of the production and distribution of TL texts as translations into TL is the fact that this strategy offers a convenient and relatively safe way of breaking with sanctioned patterns and introducing novelties into a culture, and not only in the realm of literature".
} 
expectativa de que um texto traduzido vá vender mais do que uma produção local, naquela comunidade?

\begin{abstract}
Seja como for, a decisão de disfarçar um texto como tradução sempre implica um ato deliberado de subordinação a uma cultura considerada importante, prestigiada ou dominante de alguma maneira. Uma tentativa é feita então para transmitir ao novo texto parte do prestígio da cultura "doadora" tal como isso aparece aos olhos das pessoas na cultura alvo, como uma forma de direcionar, ou mesmo manipular, a recepção do novo trabalho pela audiência desejada ${ }^{4}$ (TOURY, 2012, p. 50).
\end{abstract}

Será que esse comentário se aplica ao caso de Júlio César de Mello e Souza, quando este opta por fazer pseudotraduções que remetem à cultura árabe? Essa cultura realmente desfrutava de tanto prestígio assim junto ao público brasileiro?

É interessante problematizar essa afirmação de Toury, já que o caso de Malba Tahan parece contrariar algumas expectativas relacionadas a pseudotraduções. A obra de Mello e Souza nos conduz para um território bastante ambíguo: a cultura árabe, que incorpora a noção de "outro" no imaginário europeu (do qual somos parcialmente herdeiros), por um lado intriga e atrai; por outro, gera uma reação de rejeição e medo, principalmente no âmbito religioso.

Dito isso, vale dizer que este estudo não visa extrair generalizações a partir de um caso específico. Afinal, este trabalho também se fundamenta na noção de micro-história, tal como esta é formulada por Giovanni Levi no ensaio "Sobre micro-história" (1992). Caracterizada por uma pesquisa intensiva em pequena escala, essa abordagem não tem como meta ajustar os casos às leis existentes, tampouco promover a generalização dos dados cruzados para gerar novas previsões. Seu objetivo é extrair "a não aparente importância das coisas" (LEVI, 1992, p. 142) e "dar expressão científica a acontecimentos simples" (ibid.).

Nessa proposta, o particular é visto como tal, sem a pretensão de representar um caso típico e sem que seus traços individuais sejam

\footnotetext{
${ }^{4}$ No original: "Be it as it may, the decision to disguise a text as a translation always implies a deliberate act of subordination, namely, to a culture which is considered prestigious, important, or dominant in some way. An attempt is thereby made to impart to the new text part of the prestige of the 'donating' culture as it is seen in the eyes of the persons-in-the-'domestic'-culture, as a way of directing, even manipulating, the reception of the new work by its intended audience".
} 
suprimidos em prol de uma generalização mais ampla. Isso não implica abrir mão de uma visão abrangente: a perspectiva da micro-história é que casos insignificantes e individuais podem sim revelar fenômenos mais amplos.

É nesse diálogo com Toury e Levi que se estabelecem os objetivos deste trabalho: (i) apontar as marcas textuais que conferem a $O$ homem que calculava uma aparência de tradução; (ii) elencar fatores que podem ter motivado Mello e Souza a apresentar sua obra como uma tradução, e não como um texto de sua autoria.

\section{Malba Tahan, o autor fictício}

A obra de Malba Tahan não foi a primeira experiência de Júlio César de Mello e Souza com pseudotradução, conforme ele mesmo contou em uma entrevista concedida ao MIS (Museu da Imagem e do Som) e citada no artigo "Malba Tahan: muito além do pseudônimo" (2015), de Pedro Paulo Salles e André Pereira Neto. No depoimento, Mello e Souza relembra sua experiência no jornal O Imparcial, no Rio de Janeiro, onde atuava como officeboy e tradutor de notícias de guerra. É curioso perceber a associação dessas duas funções, sinal de que a atividade tradutória era uma das muitas tarefas atribuídas ao "faz tudo". Faz sentido, se lembrarmos, como base nas pesquisas de Lia Wyler (2003), que até quase a segunda metade do século $\mathrm{XX}$, no Brasil, "a tradução teve predominantemente o caráter de exercício acadêmico ou prazeroso e de ocupação temporária para as elites intelectualizadas" (WYLER, 2003, p. 51). Ou seja, não era vista como uma profissão de fato.

Isso se deve, em parte, ao fato de que, até o século XIX, a população brasileira se dividia em uma maioria analfabeta e uma minoria que dominava não apenas o português, como também o francês (reflexo de uma sociedade profundamente desigual). Ou seja, a maior parte da população não conseguiria ler uma tradução, enquanto a elite não precisava dela, pois podia ler os livros que quisesse em francês. Não havia, portanto, uma demanda que estimulasse o desenvolvimento da profissão de tradutor de livros (ibid., p. 61).

Após esse breve aparte, voltemos a Mello e Souza em sua passagem pelo jornal O Imparcial. 
Certa feita, Julio entregou ao editor do jornal um conto de sua autoria, esperando que ele fosse publicado. Passados os dias, o conto permanecia sobre a mesa do editor debaixo de um chumbo de linotipo (...). Depois de verificar várias vezes e constatar que seu conto permanecia com o "chumbo em cima", tomou-o de volta sorrateiramente e, onde se lia J.C. Mello e Souza, escreveu outro nome: R.V. Slady - nome que ele inventou na hora. (...) ao reencontrar o editor, disse-lhe, simulando convicção: "Aqueles contos que eu trouxe eram realmente muito fracos, não valiam nada. Mas descobri um escritor americano formidável, que é muito curioso. Traduzi - graças ao auxílio de um esperantista - os contos dele, que são desconhecidos no Brasil" (SALLES; PEREIRA NETO, 2015, p. 3).

No dia seguinte, um dos contos de Mello e Souza foi publicado, levando o jovem escritor à seguinte conclusão: “Eu raciocinei: Quando é JC Mello e Souza: chumbo em cima! Quando é R.V. Slady: destaque na primeira página...!?" (ibid.). A partir desse evento, Mello e Souza começa a se dedicar a novas pseudotraduções, agora atribuindo-as a um autor árabe, chamado Malba Tahan. Para conferir credibilidade à criação, Mello e Souza passou cinco anos estudando a cultura e a língua árabe com Ragy Basile e Jean Anchar (ibid., p. 4).

Em 1924, Mello e Souza procurou Irineu Marinho com uma série de contos e uma proposta: publicar no jornal $A$ Noite aqueles textos de cunho educativo e moral, ambientados no Oriente, como se estes fossem obra do árabe Malba Tahan. Após ler alguns contos, Marinho deu seu aval, e os textos começaram a ser publicados, como traduções. O plano foi tão bem-sucedido que, já em 1925, deu origem a um livro: Contos de Malba Tahan.

A farsa estava funcionando. Uma matéria publicada na revista Careta em 1925, com o título "O esperanto e as literaturas ignoradas", chegava a dizer o seguinte:

Inquestionavelmente, o estudo do esperanto está se tornando indispensavel a quem quizer conhecer todas essas literaturas tão interessantes e tão ignoradas. Com effeito, quasi todas as obras typicas dos bons escriptores estão traduzidas para o idioma auxiliar. Turgeneve, Raahe, Eliza Orzesko, Salom-Alekém, Stamatov, Arisima, Dorosevich, Malba Tahan, Omar Khayyan, Tagore e innumeros outros, já podem ser lidos, independentemente do francez e do inglez em que raras de suas obras existem traduzidas - caso existam! - e às vezes, sem a indicação leal da verdadeira proveniência (Careta, 1925, ed. 0870, p. 4). 
Mello e Souza demonstrou ser um escritor altamente profícuo. Pouco depois dessa estreia, lançou Céu de Allah (1927); seguido por Amor de beduíno (1929); Lendas do deserto (1929); Mil histórias sem fim (1931). Em 1931, ele lançou pela primeira vez livros que levavam seu próprio nome - tratavamse de quatro livros didáticos. Estima-se que, entre 1925 e 1975 (ano em que morreu), ele tenha lançado 118 livros (entre obras suas e de Malba Tahan), sem contar as diversas colaborações para jornais e revistas ${ }^{5}$.

Como vemos, a estratégia adotada por Júlio César de Mello e Souza tinha um viés mercadológico e foi realizada em parceria com uma casa editorial, o que conferia credibilidade à empreitada. Porém, é preciso destacar que essas pseudotraduções não se aproveitavam da fama prévia de um escritor estrangeiro, tampouco se beneficiavam da receptividade desfrutada pela produção cultural de um país dominante - na verdade, o Brasil era um país bastante francófilo na época. As pseudotraduções de Mello e Souza se destacam por tornar famoso um escritor fictício, associado a uma cultura cuja influência era periférica no Brasil, em uma farsa que durou um tempo considerável.

Oito anos se passaram até que a real identidade do autor viesse à tona. Em 1933, uma leitora, chamada Rosalina Coelho Lisboa, percebeu que Kipling (apontado como tradutor da obra Sama-Ullah, contos orientais) nunca havia feito aquele trabalho. Essa história é resgatada por Moysés Gonçalves Siqueira Filho na tese "Ali Iezid Izz-Edim Ibn Salim Hank Malba Tahan: Episódios do nascimento e manutenção de um autor" (2008).

\begin{abstract}
Mello e Souza, por distração ou provocação, havia colocado em um de seus livros uma relação das "Obras de Malba Tahan", com informações sobre tradutores. (...) A descoberta feita por Rosalina não teve força suficiente para interromper a carreira do autor-personagem Malba Tahan. Havia no imaginário de seus leitores, entre 1925 e 1933, dois autores com diferentes estilos de escrita. Malba Tahan escrevendo sobre temas orientais pelas editoras Braslux, Francisco Alves, A Encadernadora, Livraria Azevedo, F. Briguiet, Freitas Bastos, Calvino Filho e Civilização Brasileira, e Mello e Souza sobre Matemática pelas editoras Francisco Alves e Getúlio Costa (SIQUEIRA FILHO, 2008, p. 45-47).
\end{abstract}

\footnotetext{
${ }^{5}$ A estimativa é do site malbatahan.com.br, que compila vasto material sobre a vida e obra de Júlio César de Mello e Souza.
} 
Quando O homem que calculava foi publicado, em 1937, já se sabia, portanto, que o verdadeiro autor do livro era Mello e Souza. O que torna o caso ainda mais curioso é notar que isso não abalou a mistificação literária junto ao público, tampouco incentivou Mello e Souza a abrir mão da tradução como forma - tanto que o romance traz notas do tradutor.

Uma busca pela hemeroteca da Biblioteca Nacional mostra que os anúncios publicitários da época continuavam a apontar Malba Tahan como autor dos livros, sem qualquer referência a Mello e Souza. Em 1943, uma matéria publicada na revista Vamos Ler! dizia o seguinte:

\footnotetext{
É tanta a maestria com que o habilíssimo ficcionista reproduz a linguagem, a psicologia e o ambiente social dos personagens que muita gente acredita achar-se diante de um verdadeiro escritor muçulmano. As próprias notícias biográficas, divulgadas pelos editores, apresentam o autor de "Céu de Allah" como nascido na aldeia de Muzalit. Mesmo porque, afim [sic] de se comprovar uma parábola, tanto faz o indivíduo ser filho de um vilarejo próximo de Meca ou da cidade paulista de Queluz (Vamos ler!, 1943, ed. 0383, 2/12/1943, p. 9).
}

O reconhecimento social do nome "Malba Tahan" era tamanho que, na década de 1950, o presidente Getúlio Vargas autorizou, por meio de um decreto especial, que Júlio César de Mello e Souza incorporasse "Malba Tahan" em sua cédula de identidade. Uma união e tanto de criador e criatura.

\section{Breno Alencar Bianco, o tradutor fictício}

No livro de estreia, Contos de Malba Tahan, Mello e Souza apontou a si mesmo como responsável pela tradução. Mas quando a obra foi reeditada, em 1929, a tarefa foi atribuída a outro nome, o de Breno Alencar Bianco. Este também é apontado como sendo o tradutor de Maktub, Aventuras do rei Baribê, Minha vida querida (com notas), Novas lendas orientais, A sombra do arco-íris e Mil histórias sem fim, além, claro, de O homem que calculava. Interessante notar que, a certa altura, Mello e Souza atribui a Bianco a autoria de um livro, intitulado Memória de um Estudante (inédito) (SIQUEIRA FILHO, 2008, p. 256).

A simples menção a um tradutor fictício já permite várias considerações. Em primeiro lugar, nota-se que a tradução é atribuída a um sujeito - ou seja, não é vista como algo que surge espontaneamente na 
cultura meta, de forma apócrifa, sem marcas individuais. Esse pode ser um sinal de valorização do profissional à frente desse tipo de atividade, que faz escolhas e responde por elas. Toury destaca a importância desse aspecto.

\begin{abstract}
Aparentemente uma trivialidade, mesmo a escolha de nomes desempenha um papel importante aqui. Na medida em que o verdadeiro autor assume agora duas diferentes funções, a do autor inventado e a do tradutor presumido, ele pode também decidir nomear um deles ou ambos, para enfatizar sua suposta diferença. $\mathrm{O}$ mais comum é que sejam criados pseudônimos, mas um dos nomes adotados pode ser real (ou seja, o verdadeiro autor às vezes é apresentado como sendo apenas o tradutor). Um dos dois (ou ambos) também podem permanecer sem nome. Os nomes também podem ser parte de um disfarce mais amplo, fornecendo pistas, por exemplo, que remetem à cultura ou língua 'estrangeira' (...). Eventualmente, um dos interesses do autor pode ser deixar algumas pistas, não muito óbvias, para tornar mais fácil a reivindicação de autoria no futuro (TOURY, 2012, p. 49). ${ }^{6}$
\end{abstract}

No que diz respeito a Bianco, estamos diante de duas curiosidades: (i) as iniciais de Breno Alencar Bianco formam "bab", termo que, em persa, indica "porta" - imagem propícia para um tradutor, como alguém que está na fronteira entre dois ambientes, permitindo que passemos de um para o outro; (ii) o nome homenageia um amigo de Mello e Souza, o General Heitor Bianco de Almeida Pedroso.

No apêndice, o nome de Bianco é precedido da alcunha "professor", o que pode ser uma pista para a profissão de Mello e Souza (que dava aula de matemática no Colégio Pedro II, no Rio), mas também pode nos servir de indício da condição social do tradutor na época. Muitas vezes, ao longo da história, a tradução foi uma atividade realizada por pessoas que exerciam prioritariamente outra atividade profissional (DELISLE; WOODSWORTH, 2003). E era dessa outra atividade que os tradutores geralmente obtinham seu status (o qual, por sua vez, poderia contribuir para a receptividade da

\footnotetext{
${ }^{6}$ No original: “Apparently a triviality, even choice of names may nevertheless play an important role here. As the real author now assumes two different functions, invented author and assumed translator, $\mathrm{s} /$ he may well decide to name one or both of these functions, to emphasize their alleged difference. The most common way is to invent pseudonyms, but one of the names may well be real (i.e., the real author is sometimes presented as just the translator). One of the functions (or both) may also remain nameless. The names may also be part of the larger guise, e.g. by hinting at the 'foreign' culture/language. Like many other features, name-giving may be likened to a dance, alternately taking a distance and coming closer. To be sure, on occasion, one of the author's concealed interests may be to leave some traces, albeit not too obvious ones, in order to make it easier to claim ownership later on, if not to be actually exposed".
} 
tradução junto ao público). O fato de um escritor ou pesquisador, por exemplo, se dedicar a traduzir uma obra específica já trazia embutida a noção de que ele reconhecia naquele texto um valor importante a ser incorporado a sua cultura e detinha o saber necessário para fazê-lo. O livro Os Tradutores na História, organizado por Delisle e Woodsworth, reúne vários exemplos nesse sentido, em que tratados médicos foram traduzidos por médicos, tratados matemáticos traduzidos por matemáticos etc. $\mathrm{E}$ a atividade tradutória muitas vezes serviu como um agente catalisador para as investigações que esse tradutor/especialista desenvolvia em determinado campo de estudo.

Bianco é apontado como professor, ainda que não seja explicitado, em nenhum momento, professor de que e onde - os paratextos dão a entender que ele conhece muito bem não só a cultura árabe como também os conceitos matemáticos ali apresentados, o que pode levar o leitor a supor que ele é especialista em alguma dessas áreas. De todo modo, o termo "professor" já contribui para conferir credibilidade à obra: se um estudioso optou por traduzir os escritos de Malba Tahan, é porque eles são realmente relevantes.

Ao associar a imagem do tradutor à de um professor, Mello e Souza também deixa entrever uma expectativa acerca da estratégia tradutória a ser empregada. Qual seja: a de que a tradução precisa se preocupar com o didatismo, facilitando a compreensão do conteúdo por parte de seus leitores/alunos. Isso fica claro na carta ao leitor assinada por Bianco em $O$ homem que calculava, na qual ele justifica algumas de suas escolhas tradutórias com base na dupla finalidade do romance, que é "educativo e cultural". Mas atenção: o apreço ao didatismo não implica aqui uma estratégia domesticadora, como veremos a seguir.

\section{As marcas de "tradução" em $O$ homem que calculava}

A história do livro se passa em Bagdá, entre os anos de 1250 e 1255. A cada capítulo, Beremiz resolve um problema (de ordem social, econômica, moral, jurídica ou estética) graças à sua excepcional habilidade matemática. O narrador é Hank Tade-Maiá, um escriba que inicia o relato com os dizeres: “Em nome de Alá, Clemente e Misericordioso!". Grafada em itálico, a frase remete a uma nota de tradução, onde é explicado que o árabe muçulmano não inicia uma narrativa sem antes fazer essa evocação a Deus. 
Em seguida, Hank Tade-Maiá começa a contar sua história: “Voltava eu, ao passo lento do meu camelo, pela Estrada de Bagdá, de uma excursão à famosa cidade de Samarra (...)". Ora, o uso do adjetivo "famosa" demonstra muita habilidade por parte de Mello e Souza, já que contribui (de maneira bastante discreta) para a sensação de que realmente estamos diante de um texto traduzido. Por meio dessa simples palavra, o narrador dá a entender que ele se dirige a alguém de seu próprio meio cultural, alguém que já está a par da fama de Samarra. Como o leitor brasileiro provavelmente nunca ouviu falar dessa cidade, faz sentido que ele suponha não ser o destinatário original do texto.

No segundo parágrafo, Hank Tade-Maiá se aproxima de Beremiz dirigindo a ele o "salã trivial dos caminhantes". Mais uma vez, vemos um adjetivo ("trivial") que sugere um conhecimento compartilhado entre autor e leitor, ambos imersos em uma suposta cultura fonte. Como o termo nada tem de trivial para o leitor brasileiro, este terá de recorrer à nota ao pé da página para saber o significado de "salã": cumprimento, saudação. Neste exemplo, assim como no anterior, o efeito almejado parece ser o de gerar no leitor brasileiro o seguinte raciocínio: "esse texto foi produzido para circular em certo contexto cultural e geográfico, muito diferente do meu; logo, tratase de um texto traduzido".

A sensação de estranhamento diante do texto persiste conforme outras palavras incomuns vão aparecendo, página após página. Entre elas, "caravançará" (p. 21)7, usada para descrever um refúgio usado pelos peregrinos, em vez da palavra "abrigo"; "parasanga" (p. 95) para se referir a uma medida adotada pelos antigos persas para mensurar certa distância (equivalente a 5.250 metros) e "ceira" (p. 122) para remeter a uma unidade de peso indiana. Outras são "jamal" (p. 22), apresentada como uma das formas com que os árabes se referem ao camelo; "xeque" (p. 25), termo usado para se referir a sábios, religiosos e pessoas que despertam respeito graças a sua idade ou posição social; "chamir" (p. 30), como são chamados os chefes das caravanas (p. 30); "mirza" (p. 43), que significa nobre, fidalgo.

As personagens circulam não pelo mercado, mas pelo "suque" (p. 45), onde fazem negócios utilizando principalmente "dinares", mas também

\footnotetext{
${ }^{7}$ As páginas aqui indicadas têm como base a 95 edição de O homem que calculava, publicada em 2020. Na ficha catalográfica, Malba Tahan aparece como autor, o livro é apresentado como ficção brasileira e não há menção a Bianco.
} 
o "timão" (moeda de ouro persa, p. 30), e expressam surpresa ou convicção com expressões tais como "Mac Allah" (p. 27), que significa "Poderoso é Deus", de acordo com a sexta nota do quarto capítulo, que traz até uma indicação de como essa expressão deve ser pronunciada: "Maque-alá". Já "Maktub" (p. 63) significa "estava escrito" e, segundo o tradutor fictício, "exprime bem o fatalismo muçulmano" (p. 63). Outras expressões são associadas a termos em português. É o caso de "Inch'Allah" (p. 65), "queira Deus", que corresponde, segundo a nota ao pé da página, ao nosso "Oxalá". Para se referirem uns aos outros, as personagens usam "samir" (amigo) ou a expressão "el-hadj" (p. 69), sendo esta reservada àqueles que já fizeram a peregrinação a Meca. Quando a palavra demanda uma explicação mais complexa, o leitor é aconselhado a consultar o glossário ao fim do livro, como é o caso de "moalakat" (p. 79), que seria um conjunto de telas, expostas na Caaba, em Meca, as quais traziam sete poemas, escritos em ouro. $\mathrm{O}$ trecho abaixo deixa claro como, em certos momentos, o texto pode soar quase incompreensível de tão estrangeirizante:

\footnotetext{
Todos os dias o calculista via-se obrigado a atender a dezenas de consultas. Ora era um cobrador de impostos que precisava conhecer o número de ratls contidos em um abás e a relação entre essas unidades e o cate; aparecia, a seguir, um haquim ansioso por ouvir de Beremiz uma explicação sobre a cura de certas febres por meio de sete nós feitos numa corda; mais de uma vez o calculista foi procurado por cameleiros, ou vendedores de incenso que indagavam quantas vezes devia um homem saltar uma fogueira para se livrar do Demônio. (...) [Mulheres] queriam conhecer os segredos que asseguram a baraka para uma esposa feliz" (TAHAN, 2020, pp. 125-126).
}

Nesse trecho, notas explicam o que é ratl (um centésimo da arroba), abás (unidade de peso empregada na avaliação de pérolas), cate (peso usado na China, equivale a 255g) e baraka (sortilégio aplicado para evitar a desgraça). Haquim, médico a quem o rei confia a saúde de suas esposas. Ainda no campo lexical, vale destacar a presença de palavras em português que derivam do árabe, tais como "álgebra" (ibid., p. 21), “alazão" (p. 25), “almofadas" (p. 37), "bazar" (p. 45), “azulejos" (p. 68), “alfafa” (p. 69), “arabesco" (p. 78), "alcatifas" (p. 93), “açucenas" (p. 94), “alaúde” (p. 101), entre outras. Não surpreende ver, ao fim do livro, na lista de referências, que uma das obras consultadas é Vocábulos portugueses derivados do árabe, de Ragy Basile. 
Cabe notar, ainda, a estranheza de algumas construções sintáticas, que dão a impressão de uma tradução literal. É o caso da expressão "a filha de meu tio", que é usada quando alguém vai se referir à própria esposa (p. 77). Situação parecida ocorre na cena em que um vizir compara boas histórias a "brincos de ouro para os meus ouvidos" (p. 41). Outra personagem comenta, acerca de uma tarefa muito difícil, que seria "mais fácil uma baleia ir a Meca, em peregrinação" do que resolver o caso (p. 63). Já a explicação que Beremiz apresenta para um problema que intrigava a todos é considerada tão "clara como leite de camela" (p. 34). Sobre a fama de Beremiz, Tade-Maiá conta que esta "galgava, a passos largos, a almenara do triunfo" (p. 35) - uma nota ao pé da página explica que almenara é o nome dado a uma torre da mesquita. Quem diria que, pouco tempo antes, Beremiz “jornadeava pelos caminhos de Alá" (p. 37) , ou seja, andava pelo mundo sem destino certo? A jovem Telassim, por quem Beremiz se apaixona, é descrita como sendo tão formosa quando "a quarta lua do mês de Ramadã" (p. 160). E Salim, dono da hospedaria, diz "aguardo as tuas ordens agora e sempre" (p. 31) em vez de "a seu dispor".

Esses trechos aludem a um tradutor que, em vez de buscar opções equivalentes para expressões idiomáticas na língua de chegada, opta por manter e mesmo acentuar as diferenças, deixando como marcado, no texto traduzido, aquilo que não era marcado no texto fonte. Traçando um paralelo com o cenário atual, apenas para esclarecer a questão, é como se, diante da expressão inglesa "it's raining cats and dogs", um tradutor escrevesse "está chovendo cães e gatos", em vez de "chovendo canivetes".

É interessante observar também uma curiosidade que diz respeito ao uso de pronomes. Nos diálogos de $O$ homem que calculava, os personagens se dirigem uns aos outros utilizando o " $\mathrm{tu}$ " ou, diante de figuras que despertam maior admiração e respeito, o cerimonioso "vós". Isso ocorre, por exemplo, quando Tade-Maiá convida Beremiz a ir com ele para Bagdá: “Numa grande capital (...) sereis auxiliar precioso para o governo. Podereis calcular populações, exércitos e rebanhos. Fácil vos será avaliar os recursos do país, o valor das colheitas, os impostos, as mercadorias e todos os recursos do Estado" (p. 19).

Ora, o "você" já era de uso corrente na produção literária nacional muito tempo antes da publicação de O homem que calculava. Mário de Andrade adota o pronome no "Prefácio interessantíssimo" (1921) - e se traz 
o "vós" na dedicatória, é para reforçar a ironia do gesto, já que esta é dedicada a si mesmo... Publicado dez anos depois, o romance Reinações de Narizinho, de Monteiro Lobato, também adota a terceira pessoa do singular nos diálogos, em vez do "tu". Já Capitães da Areia, livro de Jorge Amado publicado em 1937 (mesmo ano de O homem que calculava) traz tanto o "você" quanto o "tu", mas este, quando aparece, é acompanhado de um verbo conjugado na terceira pessoa, conforme se observa na fala, em muitas regiões do país: "Tu é bom, Grande. Tu é melhor que a gente. Gosto de você" (AMADO, 2003, p. 23).

É provável que Mello e Souza tenha adotado "tu" e "vós" para acentuar a distância geográfica e temporal que separa o leitor brasileiro das personagens da história - situadas em Bagdá, no século XIII. Mas também é possível levantar outra hipótese, desta vez mais ligada à questão da pseudotradução e às estratégias adotadas para conferir a esse tipo de texto uma aparência mais convincente.

Para apresentá-la, precisamos retomar o que diz o teórico israelense Itamar Even-Zohar em um texto seminal: "The Position of Translated Literature within the Literary Polysystem" (1990). Nesse artigo, o autor discute como a literatura traduzida pode, conforme o contexto, exercer dois papéis diametralmente distintos: ora ela propicia a introdução de novidades no centro do polissistema literário, ora ela atua para a conservação da norma. Esses dois cenários podem até coexistir, com parte da literatura traduzida exercendo essa função transformadora, enquanto outra parte se volta a medidas conservadoras. Mas o mais frequente, segundo o próprio EvenZohar, é que a tradução se localize em uma área periférica do polissistema literário e exerça um papel conservador.

[Nesse caso,] enquanto a literatura original contemporânea pode seguir desenvolvendo novas normas e modelos, a literatura traduzida adere a normas que podem ter sido rejeitadas pouco antes ou mesmo há bastante tempo pelo (recém-estabelecido) centro. (...) Um paradoxo muito interessante se manifesta aqui: a tradução, por meio da qual novas ideias, itens e características podem ser introduzidas em uma literatura, se torna um meio para a preservação do gosto tradicional (EVEN-ZOHAR, 1990, pp. $48-49)^{8}$.

\footnotetext{
${ }^{8}$ No original: "Translated literature in this case becomes a major factor of conservatism. While the contemporary original literature might go on developing new norms and models, translated literature
} 
De volta às páginas de $O$ homem que calculava, agora com o comentário de Even-Zohar em mente, propomos a seguinte questão: será que o uso do "tu" e do "vós" visa conferir ao romance O homem que calculava um tom deliberadamente mais conservador, de modo a distanciá-lo da linguagem mais arrojada que se via na literatura brasileira da época, mas aproximandoo das traduções que circulavam no período?

Para responder essa questão de modo consistente, seria preciso um novo levantamento, comparando textos da época, o que não é o foco do presente trabalho. Por enquanto, fica aqui a constatação dessas marcas textuais, como ponto de partida para investigações futuras.

Para além dos aspectos que podemos identificar na narrativa, propriamente dita, vale mencionar outro fator que contribui muito para que O homem que calculava tenha uma aparência de tradução: a presença de um volume considerável de paratextos. São atribuídas a Bianco, o tradutor fictício, um total de 192 notas, uma carta ao leitor, um apêndice e um glossário. Esse material é alvo de uma outra análise, ainda em andamento.

Neste trabalho, destacaremos apenas uma pequena parte do apêndice, por entender que ela traz uma pista valiosa para responder outra questão aqui levantada: que fatores que podem ter motivado Mello e Souza a apresentar sua obra como uma tradução, e não como um texto de sua autoria?

\section{A disputa entre dois modelos distintos de ensino da matemática}

Como vimos no início deste artigo, Toury afirma que as pseudotraduções podem ser motivadas pelo desejo de promover inovações em determinada cultura, aproveitando-se da maior tolerância que o público leitor demonstra ter em relação aos desvios ali presentes. Isso leva à pergunta: que posições apresentadas e/ou defendidas em $O$ homem que calculava desafiavam o discurso dominante?

É diante dessa pergunta que ganha relevância uma simples nota localizada no apêndice, na parte "Considerações sobre os problemas

adheres to norms which have been rejected either recently or long before by the (newly) established center. It no longer maintains positive correlations with original writing. A highly interesting paradox manifests itself here: translation, by which new ideas, items, characteristics can be introduced into a literature, becomes a means to preserve traditional taste". 
propostos", em que algumas das situações apresentadas ao longo do livro são retomadas, para detalhar a solução dada por Beremiz ou mostrar formas alternativas de resolver a questão.

No trecho dedicado a um dos casos abordados no livro - o "Problema do Joalheiro" - nos deparamos com uma citação atribuída a André Huisman, reproduzida a seguir: “É preciso que o professor se esforce no sentido de dar um caráter concreto aos problemas que apresenta aos estudantes" (TAHAN, 2012, p. 262). Essa frase é acompanhada por uma nota, onde encontramos as referências bibliográficas da citação (Le Fil D'Ariane, Paris, 1959) e um comentário de Bianco - onde, contudo, é a voz de Mello e Souza que se faz ouvir, como se este finalmente saísse dos bastidores do romance e se revelasse sem disfarces ao leitor:

\begin{abstract}
Observa Huisman, no Avant-Propos de sua obra, que se faz necessária uma transformação radical no ensino da Matemática. Até por suas aplicações, nos exercícios que figuram nos compêndios didáticos, a Matemática aparece distorcida, fora da vida real. No Brasil, já assinalamos, da parte de muitos professores, essa preocupação de modernizar a Didática da Matemática. O Prof. Manuel Jairo Bezerra é, sem dúvida, um dos grandes paladinos dessa campanha renovadora. Sem o recurso do Laboratório (...) o ensino da Matemática é defeituoso, deficiente e obsoleto (TAHAN, 2012, p. 262).
\end{abstract}

É verdade que por todo o livro está latente a mensagem de que conceitos matemáticos podem ser ensinados por meio de situações concretas, assim como a noção de que o saber matemático também possui sua historicidade, seus personagens, suas reviravoltas. Mas toda essa abordagem se dá num contexto "estrangeiro".

Essa nota que acabamos de ver mostra ao leitor que tal abordagem não é uma especificidade da cultura árabe, e sim uma questão também em debate no Brasil. O conteúdo deixa claro, para o leitor que não estivesse a par da disputa que se desenrolava no campo da educação, que havia uma campanha em curso, em prol da modernização do ensino de matemática. E Mello e Souza estava alinhado à "campanha renovadora".

O Ministério da Educação era um órgão recente; tinha sido instituído em 1930 (ou seja, poucos anos antes da publicação de $O$ homem que calculava). Sua criação estava entre os primeiros atos do Governo Provisório de Getúlio 
Vargas. A pasta foi entregue ao mineiro Francisco Campos, que buscou imprimir "uma tendência renovadora, em âmbito nacional" (SIQUEIRA FILHO, 2008, p. 135).

\begin{abstract}
Uma das principais características dos escolanovistas era a de criticar, sob a égide do "aprender fazendo", um tipo de ensino predominantemente intelectualista e livresco valorizado pela escola tradicional, porém, contrapondo esses princípios, propuseram métodos ativos de ensinoaprendizagem" (ibid., pp. 135-136).
\end{abstract}

Segundo Siqueira Filho, o mentor intelectual por trás dessa proposta era Euclides Roxo, sócio-colaborador da Associação Brasileira de Educação (ABE), organização que funcionava como centro responsável pela divulgação dos propósitos do movimento renovador. A ABE nasceu em um momento de transformações significativas (tanto no quesito político, como econômico e educacional) e estava "calcada no conflito entre os adeptos da escola renovada e os católicos conservadores, que detinham o monopólio da educação elitista e tradicional, bem como, nas contradições políticas ocasionadas pelos vários setores das camadas dominantes na estrutura do poder" (SIQUEIRA FILHO, 2008, p. 137).

Roxo já havia promovido uma série de mudanças no Colégio Pedro II - onde Júlio César de Mello e Souza era professor. Ao ser convidado por Campos para participar da elaboração da reforma do ensino em âmbito federal, Roxo viu a oportunidade de levar as mudanças que tinha implementado no Pedro II a uma escala muito maior. Uma das mudanças propostas previa unir em uma só disciplina (a matemática) três áreas que eram ensinadas separadamente: aritmética, geometria e álgebra. Naturalmente, isso demandava uma adaptação por parte dos professores, e houve reação.

Outro grupo diretamente interessado na implementação ou não das mudanças era o dos autores de livros didáticos - grupo do qual Mello e Souza fazia parte. O mercado de livros didáticos estava em expansão, o que afetava financeiramente as editoras, com impacto direto em suas perspectivas de crescimento.

Muito provavelmente, tanto o ensino tradicionalmente livresco para se ensinar Matemática, quanto a preocupação com a quantidade de livros 
didáticos disponibilizada no mercado, sob a antiga orientação, o que, conseqüentemente, se converteria em prejuízos para todos os envolvidos, contribuíram para que professores-autores se posicionassem resistentes à unificação dos três ramos matemáticos e, com isso, Roxo acabara por tomar parte em uma polêmica, repercutida em uma série de artigos publicados em jornais, com Joaquim Inácio de Almeida Lisboa, catedrático de Matemática do Colégio Pedro II, seu colega de trabalho, mas contrário às suas propostas. (SIQUEIRA FILHO, 2008, p. 139).

Ao cativar crianças e jovens por meio de textos de Malba Tahan, Mello e Souza talvez buscasse ganhar adeptos para a campanha renovadora, mostrando por A + B que era possível associar o ensino de matemática a problemas cotidianos e que essa abordagem obtinha mais engajamento junto aos alunos. Outro elemento, ainda não mencionado, é que esse novo olhar para o ensino da matemática também valorizava a historicidade da disciplina, mostrando como ela foi se desenvolvendo ao longo do tempo.

Esse resgate histórico passava pelo reconhecimento do legado deixado pelo povo árabe, que não só foi responsável por vários avanços na área como exerceu um papel fundamental na preservação e divulgação do saber desenvolvido pelos gregos na Antiguidade. Um dos textos que compõem o apêndice de O homem que calculava ("Os Árabes e a Matemática") é destinado justamente à valorização desse legado e termina com a afirmação de que "o povo árabe (...) foi o povo que mais colaborou para o progresso moral e material da Humanidade" (TAHAN, 2012, p. 253). Ao trazer esse discurso para a dimensão literária, Mello e Souza mais uma vez ia na contramão da percepção prevalente.

Como observa Valter Luciano Villar, na tese "Os árabes e nós: a presença árabe na literatura brasileira" (2012), uma das coisas que nós "herdamos" durante a colonização foi a perspectiva europeia sobre os árabes, que encarnavam a própria noção do "outro", do não civilizado. E uma das formas como essa rejeição se manifesta é por meio do apagamento, no Ocidente, de tudo aquilo que foi legado pelo povo árabe.

\footnotetext{
Cronistas, colonialistas e poetas, a serviço do império lusitano, assumem atitudes de hostilidade cultural, em relação ao mundo árabe e islâmico, gerando, como produto dessa notável ausência de alteridade, na moderna percepção ocidental, condutas e tendências cada vez mais uniformizadoras e estereotipadas acerca do povo árabe (VILLAR, 2012, p. 13).
} 
Os traços dessa hostilidade também podem ser identificados em vários textos literários produzidos no Brasil, observa Villar, ainda que os brasileiros não tivessem nenhuma relação direta com o povo árabe. A esse olhar de franca oposição, seguiu-se um período em que as potências europeias se dedicaram a iniciativas voltadas ao estudo do Oriente, incluindo o mundo árabe.

\footnotetext{
É nesse momento que grandes nomes do meio intelectual europeu lançamse em longas viagens, para conhecer o Oriente, entre eles Chateaubriand, que muito dialogou em seus textos, preenchidos de exotismo, com os poetas e escritores do romantismo brasileiro da segunda fase (...). O resultado dessa vasta iniciativa foi a criação de escolas e instituições europeias, como a Royal Asiatic Society, a Societé Asiatique, e Deutsche Morgenlandische, que sistematizaram os conhecimentos sobre as comunidades colonizadas, em especial as comunidades árabes, fornecendo, assim, um corpo crítico de estudos que possibilitaria ao europeu comum conhecer o mundo oriental sem empreender longas viagens. Com efeito, foi se realizando uma ampla e difusa coleção de textos estéticos, eruditos, sociológicos, antropológicos, entre outras séries de interesses colonialistas, que buscava, acima de tudo, comparar o mundo em estudo, com o mundo europeu, primando esse último pela ideia de superioridade (...) Como consequência, disseminou-se um discurso que buscava legitimar a necessidade de levar os benefícios da civilização branca e europeia à comunidade de povos colonizados, entre eles, os árabes (VILLAR, 2012, pp. 36-37).
}

A primeira onda de imigrantes árabes para o Brasil se dá na passagem do século XIX para XX, apenas. Justamente no "momento em que os intelectuais brasileiros, na esteira das propostas eurocêntricas, propuseram a teoria do 'branqueamento'", escreve Villar (2012, pp. 38-39). Esses imigrantes árabes eram, em sua maioria, cristãos - foi a partir da década de 1920 que uma minoria muçulmana também começou a desembarcar no país. Ainda assim, cabe destacar que, mesmo no caso dos árabes cristãos, os ritos e dogmas diferiam dos adotados no catolicismo romano.

Como se sabe, a política de imigração previa uma assimilação dos estrangeiros (fosse qual fosse sua origem) à realidade brasileira, e isso envolvia até o uso de medidas repressivas contra tudo que pudesse vincular o imigrante a sua cultura de origem, inclusive a língua, como aponta Helder Macedo de Held na dissertação "O homem que orientalizava: o oriente de Malba Tahan" (2012). Esse processo de assimilação, escreve Held, "foi tido 
como questão de segurança nacional, ao passo que fazia parte do processo de elaboração de uma identidade em busca de formação de um novo brasileiro, tendo como premissa a substituição dos símbolos étnicos por outros representativos da brasilidade" (HELD, 2012, p. 45).

Ao contrário dos imigrantes europeus, que se fixaram em colônias e se dedicaram inicialmente à agricultura, os árabes se instalaram, em sua maioria, no meio urbano, e se dedicaram ao comércio - elementos que facilitaram sua interação com os brasileiros. "Essa rápida capacidade de adaptação à nova pátria impressionou alguns escritores que fizeram deles personagens de seus enredos, tal como Jorge Amado" (ibid., p. 82), diz Held. Mas, como ele mesmo afirma, a postura adotada por Júlio César de Mello e Souza se distingue bastante da do escritor baiano, que mostra o árabe inserido na realidade nacional, já adaptado.

\begin{abstract}
Nos enredos criados por Júlio César de Mello e Souza, o árabe é apresentado ao nacional pelos seus costumes, sua religião, seu modo de expressar seus sentimentos e pela sua língua. Logo, ainda como díspare, distante. (...) Em um período em que os literatos contemporâneos pensavam um projeto nacional, Júlio César de Mello e Souza aproveitou-se do aumento do número de leitores e do surgimento de um mercado livreiro para criar uma obra que atraísse a atenção exatamente por retratar o outro. $\mathrm{O}$ que antes era desconhecido para o leitor brasileiro passava a fazer parte do seu cotidiano; o que parecia distante na geografia passava a ficar mais próximo no campo da cultura. (...) Ao ambientar seus contos e romances no mundo árabe, o escritor idealizava seus personagens por meio de certas características culturais e pessoais adequadas ao estilo ocidental, mas sem retirar o seu status de diferente. Oposto à ideia de retratar o pátrio, sua gente e sua natureza, a maior parte de sua bibliografia não teve o nacionalismo como critério de qualidade literária; portanto, não se enquadrou nas preocupações de maior parte dos literatos contemporâneos a ele (ibid., pp. 82-83, grifos meus).
\end{abstract}

\title{
7. Conclusão
}

Escrito por um brasileiro, mas apresentado ao público como sendo um livro árabe, o romance $O$ homem que calculava é muito rico em elementos que interessam diretamente aos Estudos de Tradução. Por limitações de tempo e espaço, a investigação aqui proposta se detém sobre uma pequena parcela deles. 
Em primeiro lugar, buscamos apontar as marcas textuais que ajudam a dar à obra uma aparência de tradução. Em segundo, levantamos alguns fatores que podem ter motivado Júlio César de Mello e Souza a apresentar seus escritos como tradução, e não como um texto original.

No que tange à primeira questão, é importante destacar as escolhas lexicais presentes na obra. Elas revelam uma abordagem estrangeirizante diante de um suposto texto fonte; e a imagem da tradução que emerge é a de uma porta que se abre para outra cultura, promovendo no leitor uma experiência de estranhamento. O uso de termos como "suque" e "mirza" que poderiam ser substituídos, respectivamente, por "mercado" e "nobre" - faz com que o leitor precise recorrer com frequência às notas de rodapé ou mesmo ao glossário ao final do livro. Isso coloca em evidência a presença do tradutor, como se este fosse um guia, sem o qual estaríamos perdidos numa terra estrangeira.

A sensação de estranhamento também é ativada pelo uso de expressões que parecem resultar de uma tradução ao pé da letra. Isso ocorre, como visto, quando algum personagem diz "a filha de meu tio" para se referir à própria esposa ou comenta que uma explicação é "clara como leite de camela".

Cabe observar, ainda, o uso de adjetivos tais como "trivial" e "famosa" para qualificar algo que nada tem de trivial ou famoso para o leitor brasileiro. Essa estratégia parece ter o intuito de despertar no público a sensação de que aquele texto não foi escrito originalmente para ele reforçando, assim, a percepção de que a obra em questão foi efetivamente traduzida. É uma forma discreta, e talvez por isso mesmo bastante eficaz, de disfarçar uma pseudotradução.

Passemos, agora, à segunda questão, em que buscamos entender por que Mello e Souza optou pelo caminho da mistificação literária. Nessa análise, ora nos aproximamos de alguns pressupostos expressos pelo teórico Gideon Toury acerca de pseudotraduções, ora nos deparamos com situações que contrariam suas expectativas.

Em sintonia com Toury, está a percepção de que Mello e Souza (assim como outros autores) recorre à pseudotradução como forma de introduzir, em sua comunidade, elementos que destoam da prática dominante. Ao apresentar seu próprio trabalho como sendo fruto de uma tradução, o autor espera diminuir a resistência do público em relação àquela novidade. No 
caso de $O$ homem que calculava, vimos que a obra foi produzida num momento em que o modelo tradicional de ensino estava sendo questionado no país, e que Mello e Souza integrava o grupo favorável às reformas. Por meio da literatura, ele divulgava um novo modo de pensar a matemática, chamando a atenção do público para a historicidade da disciplina e sua conexão com os problemas do dia a dia. Era um debate que envolvia diversos atores, incluindo outros escritores e editoras, diretamente interessados em um mercado crescente: o dos livros didáticos.

Além disso, vimos que a posição de Mello e Souza também é dissonante quando se trata do papel que um artista supostamente deveria assumir na construção da identidade nacional brasileira. O livro Contos de Malba Tahan é de 1925 - foi publicado apenas três anos depois, portanto, da Semana de Arte Moderna. Mas, diferentemente dos grandes nomes do modernismo brasileiro, como Mário de Andrade e Oswald de Andrade, que estavam interessados em discutir quem somos, ele lança mão de uma pseudotradução para escrever sobre o outro, sobre um povo diferente.

Contrariando as previsões de Toury, porém, Mello e Souza não tentou se beneficiar do prestígio de outro autor, de outra língua, para gerar interesse pelo próprio trabalho. Ao contrário, se voltou para os árabes povo mal visto pela tradição europeia, o que acabou por interferir na nossa própria percepção.

É muito curioso observar que, partindo de posições periféricas (em vários aspectos), Mello e Souza tenha sido capaz de arregimentar uma legião de leitores. Mais curioso ainda é constatar que, mesmo depois que a farsa veio a público, o nome de Malba Tahan não perdeu seu apelo junto ao público, tampouco Mello e Souza abandonou as pseudotraduções. Elas continuaram a ser publicadas, com direito a notas e outros paratextos assinados por Breno Alencar Bianco, o tradutor fictício.

\section{Referências}

AMADO, Jorge. Capitães da Areia. $110^{a}$ edição (69ª edição Record). Rio de Janeiro: Record, 2003

DESLILE, Jean; WOODSWORTH, Judith (Org.). Os tradutores na história. Tradução de Sérgio Bath. São Paulo: Ática, 2003. 
EVEN-ZOHAR, Itamar. The Position of Translated Literature within the Literary Polysystem. In: Polysystem Studies [Poetics Today, Vol. 11:

1]. Durham NC: Duke University Press, pp. 45-51, 1990.

HELD, Helder Macedo de. O homem que orientalizava: o Oriente de Malba Tahan. Assis, São Paulo, 2020. Dissertação (Mestrado em História e Sociedade) - Faculdade de Ciências e Letras de Assis - Universidade Estadual Paulista. Disponível no link:

https://repositorio.unesp.br/bitstream/handle/11449/93361/000706576.pdf?s equence=1\&isAllowed=y . Acesso em: 26/11/2020.

LEVI, Giovani. Sobre a micro-história. In: BURKE, Peter (org.). A escrita da história: novas perspectivas. Tradução de Magda Lopes. São Paulo: Editora Unesp. 1992.

SALLES, Pedro Paulo; PEREIRA NETO, André. Malba Tahan: Muito além da tradução. Anais da Mostra do CAEM 2015 (Centro de Aperfeiçoamento do Ensino da Matemática - IME/USP). Disponível em: https://www.ime.usp.br/caem/anais_mostra_2015/arquivos_auxiliares/pale stras/Palestra3_Pedro_Salles.pdf. Acesso em: 26/11/2020

SIQUEIRA FILHO, Moysés Gonçalves. Ali Iezid Izz-Edim Ibn Salim Hank Malba Tahan: Episódios do nascimento e manutenção de um autorpersonagem. Campinas, São Paulo, 2008. Tese (Doutorado em Educação) da Faculdade de Educação da Universidade Estadual de Campinas.

TAHAN, Malba. Vamos Ler! Rio de Janeiro, 2 dez. 1943. Disponível em: http://memoria.bn.br/DocReader/DocReader.aspx?bib=183245\&Pesq=\%22al deia\%20de\%20muzalit\%22\&pagfis=19879 . Acesso em: 26/11/2020.

TAHAN, Malba. O homem que calculava. 95a ed. Rio de Janeiro: Record. 2020.

TOURY, Gideon. Pseudotranslations and their significance. In:

Descriptive Translation Studies - and beyond. Philadelphia e Amsterdam: John Benjamins Publishing Co. 2012.

VILLAR, Valter Luciano Gonçalves. Os árabes e nós: a presença árabe na literatura brasileira. João Pessoa, Paraíba, 2012. Tese (Doutorado em Literatura e Cultura) - Universidade Federal da Paraíba. Disponível em: http://www.cchla.ufpb.br/ppgl/wp- 
content/uploads/2013/06/images_pdf_ValterLuciano.pdf. Acesso em: 26/11/2020.

WYLER, Lia. Línguas, poetas e bacharéis: uma crônica da tradução no Brasil. Rio de Janeiro: Rocco, 2003.

\title{
Resumo
}

Lançado em 1937, o romance O homem que calculava é um verdadeiro fenômeno editorial - segue sendo reeditado no Brasil, foi traduzido para vários idiomas e já inspirou diversas pesquisas. Contudo, um aspecto do livro permanece pouco estudado: o fato de que ele é uma pseudotradução. Afinal, embora seja atribuído ao árabe Malba Tahan (e inclua até notas do tradutor), ele foi escrito por um professor brasileiro. A análise desse romance pela perspectiva dos Estudos da Tradução ilumina elementos formais e semânticos do texto, contribui para a compreensão da época em que foi produzido e evidencia como a historiografia da tradução no Brasil tem casos ricos e complexos.

Palavras-chave: Pseudotradução; Estudos descritivos da tradução; Malba Tahan

\begin{abstract}
The novel The man Who Counted (1937) is a very successful case in Brazil's literary system. The book has been translated into several languages and has already inspired a number of researchers. However, one aspect of this novel remains poorly studied: the fact that it is a pseudo-translation. The book, written by a Brazilian teacher, was presented as a translation of a fictional Arabian author named Malba Tahan and even shows translation notes. An analysis of this novel from the perspective of Translation Studies can highlight some formal and semantic elements of the text. Moreover, it helps us understand the context in which it was written and shows how the historiography of translation in Brazil includes rich and very complex cases. Keywords: Pseudotranslation, Descriptive Translation Studies; Malba Tahan
\end{abstract}

